\title{
Construction of Multimedia Teaching Platform for Community Nursing Based on Teaching Resource Library Technology
}

\author{
https://doi.org/10.3991/ijet.v12i07.7215 \\ Pan Li \\ Xiangnan University, Chenzhou, China \\ Chunyan $\mathrm{Li}^{*}$ \\ Xiangnan University, Chenzhou, China \\ pp18075531160@163.com
}

\begin{abstract}
-with the development of information technology, multimedia teaching appears in college education and brings great convenience for college teaching. The teaching resource library is the core part of multimedia teaching. This paper started from the establishment of 3D interactive model in teaching resource library, then discussed the construction of a new multimedia teaching platform and constructed the multimedia teaching platform from the aspects of picture library establishment, animation library and video library establishment, interactive 3D animation library establishment, overall structure of the platform and interface display. Then, the teaching platform was applied in teaching practice to test its effect. The contrastive analysis shows the application of teaching resource library in multimedia teaching of Community Nursing can effectively improve students' learning interest and optimize the teaching effect.
\end{abstract}

Keywords-Multimedia; Community Nursing; teaching; teaching resource library

\section{Introduction}

As Internet technology develops to broadband, high speed and multimedia directions, and college education scale expands continuously, teaching resource library technology has driven the rapid development of education informatization in a more humanized manner. The appearance of teaching resource library technology relieves the problem of the lack of teaching resources in colleges [1]. The teaching resource library means the boring knowledge points are made into digital materials by modern information technology and are finally classified according to the subject on the basis of knowledge points in the course [2]. The appearance and development of teaching resource library are closely related to information technology. The teaching resource library provides the resources with rich content and diversified forms. For example, the application of teaching resource library technology in multimedia teaching can provide students with efficient storage management, provide users with convenient 
and fast access function and provide managers with resource access effect evaluation and analysis. Based on the above advantages, teaching resource library has been applied and promoted in multiple subjects [3].

\section{Research Reviews}

Kumar et al. [4] proposed Structural and Biochemical Database (SBD) which is a multi-investigator project. SBD aims to present and manage morphological and biochemical information, and it is a phyloinformatics tool for the scientific community. Besides, it also serves as a significant resource for teaching mycology. The teaching results show that such new teaching resource library is valuable for teaching and education workers, students and the public. United States Department of Agriculture [5] also established a database redesign project for its National Animal Germplasm Program (NAGP). This example offers a precious context for teaching and implementing database analysis, design, and implementation skills, and it can serve as the foundation of a semester-long group project. The example proves that the extensive applicability of database skills in domains beyond typical business applications. The teaching resource library offers several opportunities for stressing design flexibility and data integrity control. In order to adapt to the development trend of "diversification, modularization, integration and networking" of computer basic course, $\mathrm{Hu}$ et al. [6] constructed the development framework of diversified teaching resource library for college computer basic course, and proved that computer basic course reform based on diversified teaching resource construction improves students' computer skill application ability, cultivates students' autonomous learning awareness and enhanced their autonomous learning ability through analyzing and surveying the teaching effect. Zhang et al. [7] followed the development thought of software engineering method, designed the course content of Research Methods in Educational Technology, produced an interactive micro-video teaching resource library based on real education and scientific research cases by themselves and applied it in the undergraduate class. It gained good reputation from students and users and also obtained a good teaching effect. The teaching resource library has been the key of multimedia course teaching link. With continuous development of teaching resource library, teaching resource interaction is required often to visualize abstract architecture. Traditional animation multimedia technology cannot meet the needs. The interactivity multimedia teaching comes into people's view. In recent years, there are many researches on this aspect in China. Wei [7] indicated that the application of Flash in chemical simulation operation could reduce resource waste and improve teaching efficiency. Beauchemi [8] constructed ChemLab multimedia teaching system in the teaching resource library of chemistry major. Chemical simulation experiment may be carried out on the system. The system greatly reduces the waste of teaching resources.

However, medical colleges are short of teaching resources [9]. How to construct the limited resources into campus teaching resource library so as to further improve teaching resource utilization rate and teaching quality? This has become key emphasis in the work of medical teaching workers. At present, the defects of medical teaching 
resource library construction exists in the following aspects. (1) Multimedia courseware applied in the traditional teaching increasingly develops in terms of precision, color, quality and simulation degree, but students' study and understanding may be easily restricted, and there is the lack of spatial accurate positioning due to the limitation of medical picture expression form, such as the structure of viscera. (2) The data in the resource library cannot be updated in time, and the materials are mostly of picture format. Thus, students' learning interest drops and they are absent-minded. They dislike or do not participate in classroom teaching activities. Some are even weary of studying. All kinds of bad emotions result in the decline of classroom learning efficiency and also affect their physical and psychological health. We should consider making the information contacted by students more diversified and making major view broader.

For the above defects, the teaching application standard of Community Nursing was innovatively proposed in this study. Besides, virtual reality $3 \mathrm{D}$ display technique was applied to construct 3D interactive platform on the basis of Flash technology. Medical pictures on the platform do not need complex notes. Users just need to move the mouse to a body structure, and the detail description of the structure will be displayed. In addition, the picture can be rotated at will so that users can observe the spatial 3D structure. Meanwhile, synchronous text display technology was used to help students view the text related to the picture knowledge while watching dynamic 3D pictures of Flash format. As well, this system owns the function of regular updating. Community nursing will be the emphasis in nursing science in China. It is found in nursing teaching that, traditional multimedia teaching does not own strong flexibility and it is abstract. Community nursing belongs to medical major. This subject synthesizes the contents of public health and nursing to maintain community health [10]. Many students feel dull and boring in community nursing teaching. In this study, the new teaching resource library was used in multimedia teaching of Community Nursing to break through the shortcoming of inflexible and abstract traditional teaching and provide the reference for modern medical teaching.

\section{Model analysis}

During constructing the teaching platform, it is necessary to digitize teaching resources, then construct the resources into animation library and video library and import them in 3D display browser. The relevant theories of 3D browser establishment and animation video synthesis are introduced as follows.

\subsection{D display browser}

To set up a 3D display browser, one principle is required: to let users adjust little. Based on OpenGL framework, 3D development function is applied to achieve adjustment of basic operation of $3 \mathrm{ds}$ files, including initialization, image transformation, image processing, image material and light. Visual difference is the key factor of forming 3D image [11]. In 3D visual system design, three important parameters 
should be figured out: eye base line B, projective plane $\mathrm{z}$ coordinate $\mathrm{zV}$ and projective plane direction $\mathrm{d}$.

To calculate the values of the three control parameters in OpenGL, it is necessary to define some other parameters as follows:

(1) zmax and zmin, z coordinate is perpendicular to the screen and points at the outside; zmax represents the nearest coordinate, and zmin represents the farthest coordinate;

(2) $\Delta x$ represents the width of projection plane model;

(3) Pneg and Ppos refer to maximum negative visual difference and positive visual difference respectively;

(4) The most important element $\mathrm{z}$ coordinate of focus zfocus

(5) Horizontal viewing angle of the model $\left(50^{\circ}\right)$.

With these parameters, the three control parameters B, zV and $\mathrm{d}$ are inferred.

$$
d=(\Delta x / 2) / \tan (\theta / 2)=1.07 \Delta x
$$

To figure out B, it is necessary to calculate Bneg that zmax projects to zfocus plane with negative visual difference, and then to calculate Bpos that zmin projects to zfocus plane with positive visual difference.

$$
\begin{gathered}
B_{\text {neg }}=p_{\text {neg }}\left[d /\left(z_{\text {max }}-z_{\text {focus }}\right)-1\right] \\
B_{p a s}=p_{p o s}\left[d /\left(z_{\text {focus }}-z_{\text {min }}\right)-1\right] \\
B=\left(B_{p o s}+B_{\text {neg }}\right) / 2
\end{gathered}
$$

To calculate $\mathrm{zv}$, it is required to solve the distance $\mathrm{n}$ between $\mathrm{zV}$ and $\mathrm{zmax}$ first.

$$
n=p_{\text {neg }} d /\left(p_{\text {neg }}+B\right)
$$

Then, we gain

$$
z_{v}=z_{\max }-n=z_{\max }-p_{\text {neg }} d /\left(p_{\text {neg }}+B\right)
$$

The above values are initialization values of the parameters. In practice application, users should adjust least and regard seeing $3 \mathrm{D}$ view parameters as the criterion.

\subsection{D animation production and synthesis}

Firstly, general modeling software is used to establish 3D model of teaching resources. Then, the model is imported in $3 \mathrm{ds}$ max for animation production. In other words, the camera tool is used to generate the animation sequence. To generate $3 \mathrm{D}$ animation, it is required to render animation frame sequence of the animation at the left viewpoint and the right viewpoint respectively. Then, 3D animation is synthesized through channel combination. Special attention should be given to the color problem in the synthesizing process. Each rendered image should be adjusted to the grey-scale 
map. After the synthesis, colors may be added. We suppose the original pixel point values are $\mathrm{Ri}, \mathrm{Gi}$ and $\mathrm{Bi}$. The following formula may be used to calculate luminance $\mathrm{Li}$, saturability $\mathrm{Si}$ and chroma Hi after the transformation.

$$
\begin{gathered}
L_{i}=\left(R_{i}+G_{i}+B_{i}\right) / 3 \\
S_{i}=1-3 \times \min \left(R_{i}, G_{i}, B_{i}\right) /\left(R_{i}+G_{i}+B_{i}\right) \\
H=\left(R_{i}+G_{i}+B_{i}\right) /\left(\lambda_{R} R_{i}+\lambda_{G} G_{i}+\lambda_{B} B_{i}\right)
\end{gathered}
$$

After the image is adjusted well, background music and dubbing may be conducted for the animation. Finally, they are integrated to form the multimedia library which can attract students visually and acoustically. Then, the multimedia library can be added in the teaching resource library.

\section{Construction of Teaching Platform}

\subsection{Establishment of image library}

It mainly involves collection of image materials and Community Nursing, arrangement and editing of the materials. The structure diagram is shown in Fig.1.

(1) The camera is used to shoot successful practice pictures in the community nursing. The resolution ratio should reach at least 300dpi. These images are used for the image library and modeling reference. To increase the capacity of image library, the images of the same kind on internet and books may be chosen through scanning or direct downloading. Besides, relevant images may be found from other multimedia teaching disks.

(2) Sorting and editing. Sorting and editing contain screening, classification, naming and editing in the late period. ACDsee software is mainly adopted to screen the images collected in the early stage. The unclear images with poor quality should be eliminated. In classification and naming, image data are sorted and classified according to different community nursing process and link for the sake of post processing. Photoshop is applied to edit and modify images as well as adjust the core and add comments. Finally, the edited images are put into the corresponding folder.

\subsection{Establishment of animation library and video library}

The establishment of animation library includes three steps: model establishment, $3 \mathrm{D}$ animation synthesis and placing the animation in the browser. The establishment of video library mainly involves video shooting and video production. The establishment process of animation library and video library is shown in Fig.2.

1. Modeling refers to the establishment of a 3D system of simulated training center for community nursing with 3D modeling software according to the features of community nursing. The ward, health assessment room, shape training room, car- 
dio-pulmonary resuscitation room and operating room are set up in the system. Meanwhile, 3D model of human body should be established as the main model for nursing demonstration. During modeling, the information in the image library may be used as the reference to trim the physical model so as to make the model in the animation more vivid. Except 3D modeling, for the modules for which it is hard to model, shooting videos or downloading videos may be conducted for supplement.

2. $3 \mathrm{~d}$ s max software is used to produce and design animation for $3 \mathrm{D}$ model. A series of processes such as cardio-pulmonary resuscitation, dressing change and patient transportation in community nursing are made into 3D animation. If the modeling difficulty it too large, video production software may be used to process the video (including editing, subtitle and special effect) and then the video may be placed in the video library.

3. For the 3D animation produced specially, it can be implemented only in the special $3 \mathrm{D}$ display browser. The $3 \mathrm{D}$ animation is imported in the $3 \mathrm{D}$ display browser, and then $3 \mathrm{D}$ animation livery of demonstration form forms.

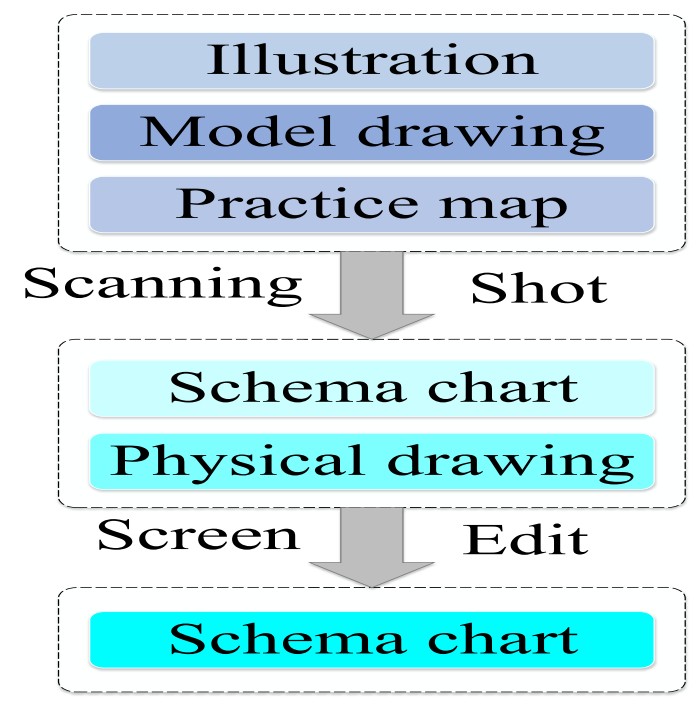

Fig. 1. Login interface
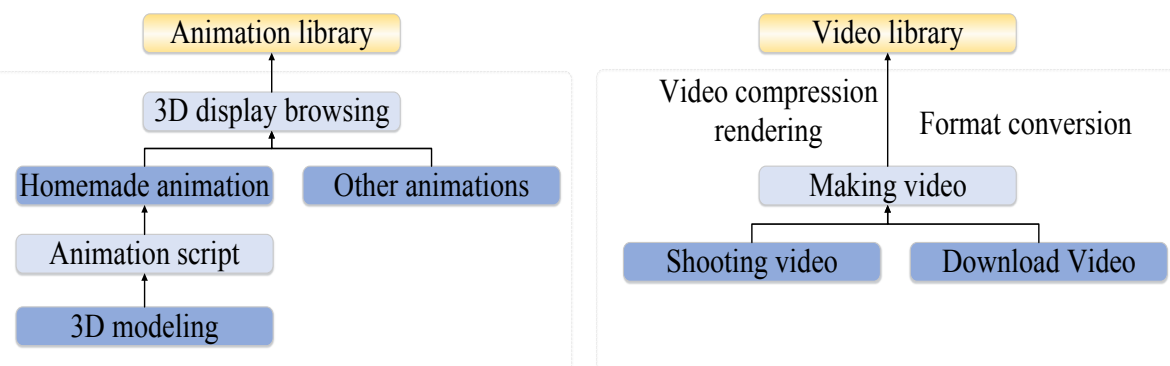

Fig. 2. Course module selection interface 


\subsection{Establishment of interactive 3D animation library}

Interactive operation platform is the largest highlight of this platform. It can provide on-spot self-regulation demonstration, including the operation commands of modeling, importing into the 3D display browser and adding 3D. The modeling is same with that in 4.2. After the established 3D model is imported into the $3 \mathrm{D}$ display browser, 3D transformation function of OpenGL framework may be used to set 3D operation functions. The operation mode of mouse + keyboard may be directly used to achieve nursing operation of 3D interface window, such as operation nursing, child healthcare and other actions. The establishment mode is shown in Fig.3.

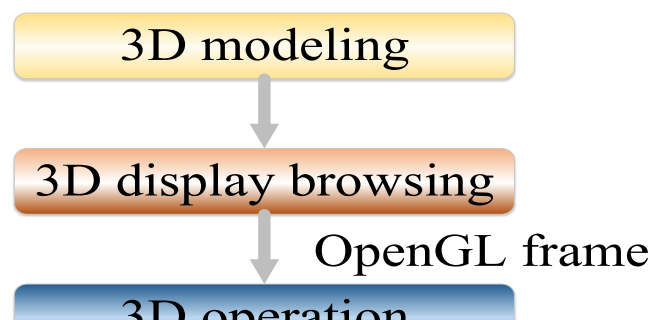

\section{D operation}

Fig. 3. Course explanation interface

\subsection{Overall structure and interface display of the platform}

The overall structure contains login interface, course library, animation library, video library and $3 \mathrm{D}$ interactive simulation library.

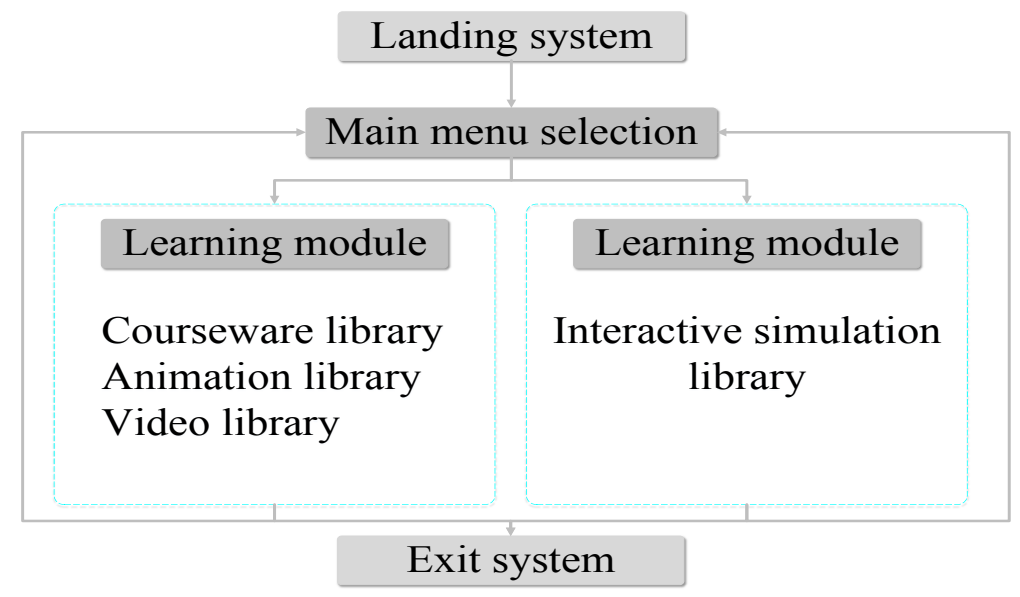

Fig. 4. Structure diagram of system framework

The two interfaces of teaching resource library of Community Nursing are shown in Fig.5 and Fig.6. 


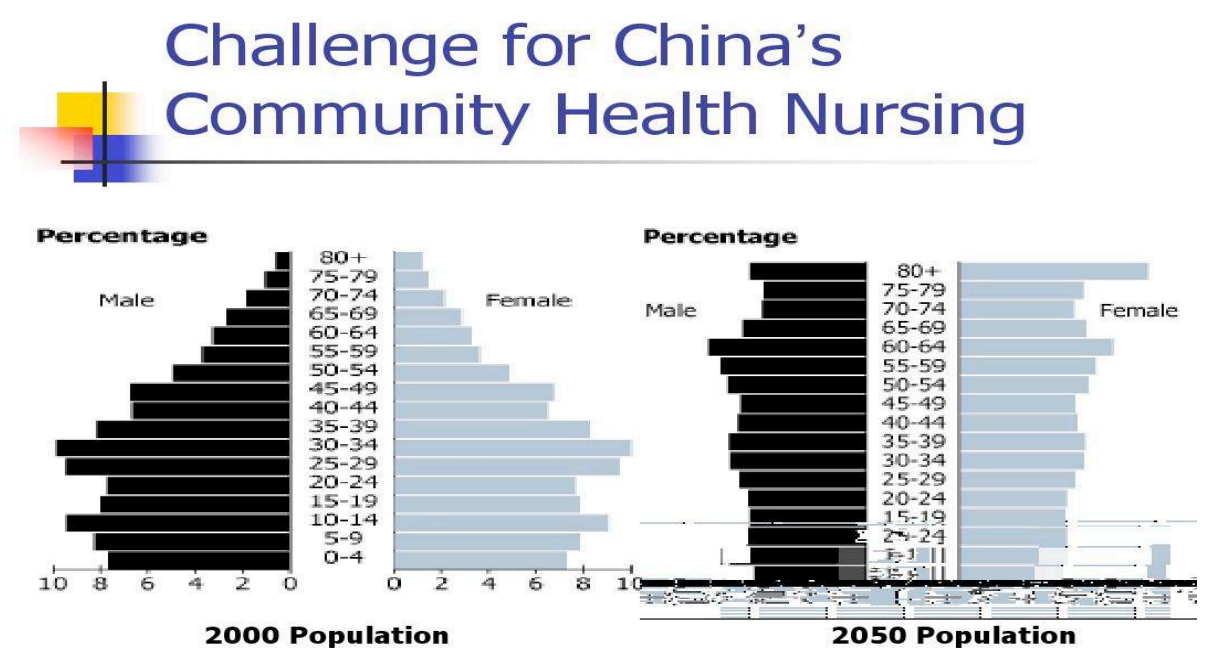

Fig. 5. Interface display of multimedia teaching in community nursing

Fig.5 shows the interface after users log in the teaching resource library. After login, users enter the selection menu and can choose learning module or operation module. Learning module provides courseware library, animation library and video library.

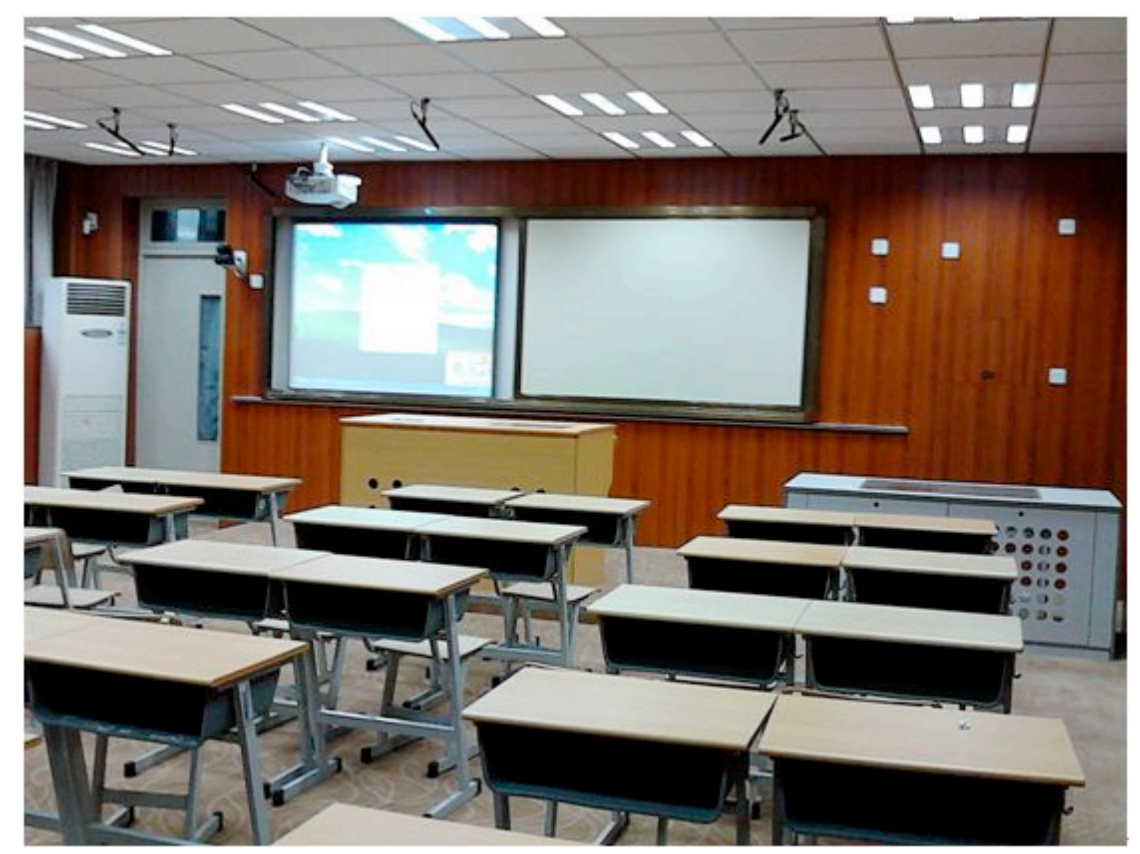

Fig. 6. Interactive multimedia classroom display in community nursing 
Fig.6 shows the interactive interface. Health assessment, shape training, cardiopulmonary resuscitation and child healthcare may be chosen. After the specific nursing operation is chosen, users will enter the interactive interface which depends on 3D display browser interface produced by visual 3D technology. Here, 3D transformation operation may be conducted.

\subsection{Teaching platform test}

To test the effect of this teaching platform, the contrast experiment was done. 400 sophomores and junior students of nursing major were chosen as the objects of study. 200 sophomores and 200 junior students were chosen. All students are female, with the age between 20 and 22 . The average learning ability of all students had no significant difference in the early stage. 100 sophomores and 100 junior students were chosen as the experimental class. The remaining 200 students served as the control group. The teachers of both classes were same. The gender, age and learning ability of both classes had no significant meaning $(\mathrm{P}>0.05)$. Traditional teaching method was applied for the control group, while this teaching platform was adopted for the experimental class. The courseware, animation library, video library and 3D interactive library in the teaching resource library were applied in the teaching process. Then, practice was carried out according to the teaching programme. The questionnaire survey results about students; evaluation of the teaching platform are shown in Tab.1. The statistical results of students' final scores are shown in Tab.2.

Table 1. Evaluation of teaching resource library by the experimental class $(n=200)$

\begin{tabular}{|l|c|c|c|}
\hline \multicolumn{1}{|c|}{ Item } & Yes & Unchanged & No \\
\hline Improve learning interest & $200(100.0 \%)$ & $0(0.0 \%)$ & $0(0.0 \%)$ \\
\hline Deepen theory understanding & $187(93.5 \%)$ & $11(5.5 \%)$ & $2(1.0 \%)$ \\
\hline Promote learning efficiency & $178(89.0 \%)$ & $18(9.0 \%)$ & $4(2.0 \%)$ \\
\hline Know well operating skills & $188(94.0 \%)$ & $11(5.5 \%)$ & $1(0.5 \%)$ \\
\hline Enhance comprehensive quality & $156(78.0 \%)$ & $33(16.5 \%)$ & $11(5.5 \%)$ \\
\hline
\end{tabular}

Table 2. Contrast of theory scores, practice scores and comprehensive ability of both classes $(\bar{x} \pm s)$

\begin{tabular}{|l|c|c|c|}
\hline \multicolumn{1}{|c|}{ Item } & Theory test & Operating skill & Comprehensive ability \\
\hline Control class & $62.57 \pm 7.26$ & $61.24 \pm 8.63$ & $63.57 \pm 9.62$ \\
\hline Experimental class & $74.25 \pm 5.63$ & $75.57 \pm 6.42$ & $76.57 \pm 7.84$ \\
\hline$P$ & $<0.05$ & $<0.05$ & $<0.05$ \\
\hline
\end{tabular}

Seeing from students' application feeling for the new multimedia teaching platform (shown in Tab.1), all students considered the new system can improve their learning interest in Community Nursing. Traditional theory teaching is too dull and boring. The new multimedia teaching platform can make the theory displayed more vividly. $93.5 \%$ of students in the experimental class thought that the new system can deepen theory understanding. $89 \%$ of students felt the new system can promote their learning 
efficiency. $94 \%$ of students expressed that the 3D interaction function provided by the new teaching platform can effectively enhance their operation proficiency. In terms of comprehensive ability improvement, $78 \%$ of students considered the new system can improve comprehensive ability. In their views, the interest is the best teacher. With strong learning interest, they can take the initiative to learn Community Nursing. So, the comprehensive ability improves. Tab.2 indicates that both classes differ a lot in theory test, operating skill and comprehensive ability. The mean score of experimental class in the three aspects is higher than that of control class. In addition, score distribution of experimental class is more uniform than that of control class. The experimental results have significant meaning $(\mathrm{P}<0.05)$.

\section{Conclusions}

In this study, 3D technology, synchronous text display technology and Flash technology were integrated into a teaching resource library for medical major. Certain effect was achieved. The teaching resource library greatly motivates learning interest of medical students, and helps the students who resist medical knowledge understand the teaching content and cultivate their comprehensive ability. We consider that the teaching resource library can be applied in classroom teaching and well display key teaching points. Moreover, it is convenient to operate and beneficial to network communication. If it can be integrated with micro-course and MOOC, it can be effectively applied in other courses of medical major. The students of other medical major may be organized to participate in expansion and improvement of the resource library in the future. The completed teaching resource library may be utilized to carry out scientific research activity. It may be expected to be applied in science popularization education of primary and secondary school students. Furthermore, learners just need a computer terminal to participate in study anytime, and there will be no any loss in teaching quality and quantity. Meanwhile, distance learning without time and place limits can be achieved.

\section{Acknowledgment}

This work was supported by the Project of Hunan Provincial Education Department (15C1280), Hunan Provincial Education Science Twelfth Five Year Plan Project (XJK015BGD068) and Hunan Provincial Education Science Thirteenth Five Year Plan Project (XJK17CGD042).

\section{$7 \quad$ References}

[1] Dai, W., Fan, L. Discussion about the Pros and Cons and Recommendations for Multimedia Teaching in Local Vocational Schools, Computer Knowledge \& Technology, 2011, vol. 33(1), pp. 1144-1148. 
Paper-Construction of Multimedia Teaching Platform for Community Nursing Based on Teaching Re...

[2] Miller, C.L. Developing a Livebinder as Teaching Resource in Family \& Consumer Sciences, Journal of Family \& Consumer Sciences, 2015, vol. 107(1), pp. 52-54.

[3] Varela-Nallar, L., Alfaro, I.E., Serrano, F.G., et al. Wingless-type family member 5A (Wnt-5a) stimulates synaptic differentiation and function of glutamatergic synapses, Proceedings of the National Academy of Sciences of the United States of America, 2010, vol. 107(49), pp. 21164-21169. https://doi.org/10.1073/pnas.1010011107

[4] Kumar, T.K.A., Blackwell, M., Letcher, P.M., et al. Research and teaching with the AFTOL SBD: an informatics resource for fungal subcellular and biochemical data, IMA fungus, 2013, vol. 4(2), 259-263. https://doi.org/10.5598/imafungus.2013.04.02.11

[5] Irwin, G., Wessel, L., Blackman, H. The Animal Genetic Resource Information Network (AnimalGRIN) Database: A Database Design \& Implementation Case, Journal of Information Systems Education, 2012, vol. 23(1), pp. 19-27.

[6] Hu, Q.T., Du, X.J., Ye, H.W. Exploration on the computer basic courses Based on the construction of multi resource teaching resources, China Educational Technology, 2011, vol. 18(5), pp. 75-78.

[7] Zhang, Y., huang, X., Xie, H.Q. Research and application of interactive micro video teaching resources -- Taking "educational technology research methods" as an example, China Educational Technology, 2013, vol. 20(5), pp. 48-54.

[8] Wei, J.L., Liu, G.L., Lu, P.Y. Flash technology for chemical experiment operation simulation, Computer Engineering and Design, 2005, vo. 26(12), pp. 3264-3266.

[9] Beauchemin, C., Cooper, D., Lachaine, J. Really reappearing of chemical experiments application of Corel ChemLab, Computers \& Applied Chemistry, 2006, vol. 23(10), pp. 1038-1040.

[10] Cheng, F., Cao, M.R. Application and thinking of multimedia technology in biochemistry teaching for nursing specialty, China Medical Education Technology, 2010, vol. 24(3), pp. 280-282.

[11] Cai, X.O. Study of 3D display information based on the mutual intension distribution of imaging light field, Optik - International Journal for Light and Electron Optics, 2013, vol. 124(20), pp. 4134-4138.

\section{Authors}

Pan Li is a lecturer in the School of Nursing, Xiangnan University, Chenzhou 423043, China (pp18075531160@163.com).

Chunyan Li (corresponding author) is a professor in the School of Nursing, Xiangnan University, Chenzhou 423043, China (xnxylichunyan516@163.com).

Article submitted 15 March 2017. Published as resubmitted by the authors 14 June 2017. 